\title{
DIRI RELIGIUS: SUATU PERSPEKTIF PSIKOLOGI TERHADAP KEPRIBADIAN AKHLAQUL KARIMAH
}

\author{
Retno Hanggarani Ninin \\ Universitas Padjadjaran \\ rhninin@unpad.ac.id
}

\begin{abstract}
Akhlaqul karimah in general is a temperament that contains elements of goodness. The characteristics consistent with morals, ethics, morality, dignity, and kindness in accordance with reference to the Quran and the Sunnah of the Prophet Muhammad. From psychologycal perspective, "self" is the aggregate related. Defined as an awareness of one's own unique existence, self is the crucial factor of regulatory and control functions over the thoughts, feelings, motives, and behavior. Accordingly, the proposed concept "religious self" can be defined as an awareness of the one's own existence in relation to God,in which the awareness of the relationship will be the critical factor that regulate and control the thoughts, feelings, motives, and behavior. Religious self is being argued as having four dimensions:Godness belief, awareness of God-self connectednes, acceptance of God's willpowertoward them, and motif of obedience to God's order. In term of akhlaqul karimah, each dimension of religious self is analogous to the concept of iman (faith), ikhsan (feel of being observed by the Divine), tawakal (resignation), and taqwa (piety), which are features indicate the quality of akhlaqul karimah. Critical review of concepts in common psychology ie religiosity, spirituality, personality, and self, offers new conceptualisation of akhlaqul karimah by the way of psychology.
\end{abstract}

Keywords: Religious Self, Akhlaqul Karimah, Religiosity

\begin{abstract}
ABSTRAK
Akhlaqul karimah atau budi pekerti luhur secara umum adalah suatu perangai yang mengandung unsur-unsur kebaikan dengan ciri yang sejalan dengan moral, etika, kesusilaan, kemuliaan, dan kebaikan sesuai dengan referensi Al-Quran dan Sunnah Rasulullah SAW. Dalam perspektif psikologi, agregat yang dilekati akhlaqul karimahsalah satunya adalah yang dikonseptualisasi sebagai "self". Dengan definisi self yaitu sekumpulan kesadaran akan eksistensi unik seseorang, yang akan menjadi faktor penentu fungsi regulasi dan fungsi kontrol individu, maka religious self (diri religius) dapat didefinisikan sebagai sekumpulan kesadaran akan eksistensi unik seseorang dalam keterhubungannya dengan Tuhan. Kesadaran keterhubungan tersebut akan menjadi faktor penentu fungsi regulasi dan fungsi kontrol atas pikiran, perasaan, motif, dan perilakunya. Berangkat dari definisi self, diajukan konsep diri religius dengan dimensi-dimensi meliputi keyakinan kebertuhanan, kesadaran keterhubungan dengan Tuhan, penerimaan akan kehendak Tuhan pada diri, dan motivasi kepatuhan pada Tuhan. Dalam konteks akhlaqul karimah, maka secara berurutan masing-masing dimensi tersebut analog dengan konsep iman, ikhsan, tawakkal, dan taqwa, yaitu fitur-fitur penciri akhlaqul karimah. Telaah sistematis dilakukan terhadap sejumlah konsep dalam ruang keilmuan psikologi yaitu religiusitas, spiritualitas, kepribadian, dan self. Tujuan penyusun mengkonstruksi konsep diri religius adalah untuk mengkonseptualisasiakhlaqul karimah dengan perspektif psikologi yang relatif lebih dipahami secara universal dalam ruang keilmuan psikologi.
\end{abstract}

Kata Kunci: Diri Religius, Akhlaqul Karimah, Religiusitas

\section{PENDAHULUAN}

Diri religius adalah konsep yang konstruksinya berpijak pada konsep dan teori self, religiusitas, dan spiritualitas. Sebagai sebuah konstruk yang baru dikonstruksi, meskipun dibangun di atas tiga bangunan 
teori yang telah ada, tahapan mengkaji kebenaran logis tetap perlu dilakukan. Makalah ini merupakanupaya menyodorkan kebenaran logis dari konstruk diri religius Islam, yang akan dilakukan dengan cara mengkaji konsep diri religius melalui perspektif Islam.

$$
\text { Pengkajian self menggunakan }
$$
perspektif Islam diperlukan, atas dasar keyakinan bahwa aspek spiritual ketuhanan menjadi bagian dari keberagamaan dan bahwa hal itu berhubungan dengan pikiran, perasaan, dan perilaku individu (Abdul Rauf, 2004), yang merupakan perangkat psikologis dari selfdan ketika ekspresinya yang bisa diobservasi oleh orang lain itulah yang lazim dikenal sebagai kepribadian (menurut terminologi psikologi) atau akhlak (menurut terminologi Islam).

\section{METODE PENELITIAN}

Makalah ini merupakan suatu upaya pengembangan ilmu pengetahuan, yaitu mengenai teori self. Metode yang ditempuh adalah mengaplikasikan proses berpikir kritis, yaitu mengkaji polemik di antara teori-teori yang mengkaji obyek yang sama. Diawali dari teori-teori umum tentang self, kemudian dianalisis dengan perspektif Islam tentang konstruk yang sama, menghasilkan proposisi baru tentang diri religius (religious self).

Kajian pustaka untuk mendapatkan kebenaran logis atas suatu konsep merupakan tahap penting dalam pengembangan ilmu pengetahuan, mengingat bahwa penelitian empiris cenderung membatasi obyek kajian hanya pada dimensi yang terukur atau teramati. Mempertimbangkan bahwa ilmu pengetahuan perlu menjawab persoalan mendasar yaitu mengenai esensi atau hakikat dari obyek yang diteliti, maka, untuk konsep ilmu pengetahuan yang relatif baru seperti "diri religius", diperlukan kajian filsafat atas obyek pengetahuannya. Manusia sebagai obyek studi, memiliki konstruk laten yaitu properti psikis yang tidak semuanya bisa dikaji melalui fakta empiris. Fakta empiris hanya sampai pada fenomena atau representasinya dalam bentuk sikap, perilaku, maupun ekspresi.

Penggunaan filsafat dalam mengkaji agregat psikis tersebut memungkinkan untuk melihat gejala secara utuh dan menyeluruh, artinya tidak berhenti pada dimensi-dimensi tertentu yang bisa terukur, melainkan menyentuh aspek yang sulit diukur namun ada, berfokus pada proses berpikir untuk menemukan kebijaksanaan melalui penemuan kebenaran, yang memiliki sifat mengkaji obyek secara menyeluruh, berusaha menemukan hakekat atau esensi terdalam dari suatu obyek, serta kehati-hatian dalam menemukan kebenaran. Nola menyebutnya sebagai metode untuk "menemukan" ilmu (Nola \& Sankey, 2007), dan menempatkan kajian konseptual atau "kegiatan berteori" ini sebagai memenuhi nilai internal atau nilai intrinsik dari ilmu.. Pada makalah ini, yang dikajiadalah aspek pengalaman dan penghayatan spiritual dari manusia, yang dalam psikologi dikonseptualisasi sebagai self, dengan perspektif religiusitas Islam sebagai karakterisasi dari self-nya, yang membuatnya sesuai untuk disebut sebagai religious self.

\section{HASIL DAN PEMBAHASAN}

Berdasarkan definisi yang berkembang tentang self, self adalah konsep yang multifaset, dengan pengertian yaitusekumpulan kesadaran akan eksistensi unik seseorang (Reber, 1985), kemudian Adler mendefinisikannya sebagai suatu kekuatan dalam diri yang berfungsi sebagai pengontrol (self control) dan pengarah (self regulation) dari motif, rasa takut, kebutuhan, dan sebagainya (Calhoun \& Acocella, 1990). Self juga diserupakan dengan personality(Quinn, 2006). Ada pula yang menganggapnya sebagai konsep yang terkait 
dengan personality (Smither \& Khorsandi, 2009), dan ada yang langsung menyebutnya sebagai personal self (Bennett, 2011), yaitu self yang pendefinisiannya difokuskan pada fitur-fitur idiosyncratic (individual) seperti misalnya trait kepribadian. Definisi tersebut menjadikan self sebagai konsep yang domain strukturnya meliputi kesadaran, identitas, energi, dan kepribadian, sedangkan domain fungsinya adalah untuk pengendali dan pengarah dari proses psikis internal dan perilaku (Schmeichel, Vohs, \& Baumeister, 2003).

Struktur self terdiri dari kesadaran yang dipengaruhi oleh lingkungan eksternal dari individu. Penelitian membuktikan bahwa representasi neural self bisa berbeda pada individu dari latar belakang budaya yang berbeda ( $\mathrm{Ng}, \mathrm{H}, \mathrm{Ha}$, \& Lai, 2010), dan representasi neural yang berbeda akan menghasilkan representasi kognitif yang berbeda pula. Survey lintas budaya(Boucher H. C., 2010)dan survey berbasis perkembangan identitas sosial (Bennett, 2011)juga mendukung konseptualisasi selfsebagai produk dari faktor-faktor sosial. Dengan fakta tersebut, maka agama sebagai salah satu elemen dari lingkungan eksternal, budaya, dan faktor sosial di luar diri individu, bisa mewarnai isi dari struktur self. Self inilah yang dikarakteristikkan sebagai religious selfatau diri religius.

Di area psikologi sosial konsep selfdilihat melalui perspektif attitude atau sikap (DeMarree, Petty, \& Brinol, 2007), sehingga diri religius juga mengandung pengertian sikap religius. Kesamaan self dengan attitude adalah pada dimensi fungsinya yaitu untuk mengarahkan pemikiran dan tingkah laku, sehingga dapat dikatakan bahwa diri yang religius akan mengarahkan individu pada pemikiran dan perilaku yang religius. Konsep self yang juga menjadi pondasi bagi pengembangan konsep religious self adalah true self, yangdidefinisikan sebagai serangkaian karakteristik bawaan dalam diri individu yang relatif permanen yang harus ditemukan oleh individu agar ia dapat memiliki kehidupan yang bermakna (Schlegel \& Hicks, 2011).

Gagasan tersebut menganggap true self sebagai manifestasi dari inti individualitas seseorang, antara lain spirit, soul, real meaning,dan fundamental nature. Teori ini melihat self sebagai sesuatu yang dihayati oleh individu itu sendiri. Frame of referencenya adalah individu. Pengertian ini membedakan konsep diri religius dari religiusitas, yang meletakkan frame of reference-nya pada religious institution seperti misalnya ditetapkannya pengetahuan agama (religious knowledge) yang harus dikuasai dan praktek agama (religious practice) yang harus dilakukan untuk bisa seseorang disebut memiliki religiusitas tinggi.

Penulis mendukung gagasan true self dalam dua hal, yaitu 1) sebagai suatu karakteristik bawaan yang bisa ditemukan oleh individu, dan 2) merupakan manifestasi spirit sertafundamental nature. Gagasan tersebut sejalan dengan keyakinan penulis yang diperkuat oleh Frager (2012) bahwa manusia adalah mahluk spiritual yang memiliki aspek spiritualitas dalam dirinya, bukan mahluk kosong. Sehingga dalam perjalanan hidup keberagamaannya, ia hanya berusaha menemukan spiritualitas itu dalam dirinya dan bukan mencari spiritualitas dari luar diri untuk dimasukkan ke dalam dirinya.

Dalam hal spiritualitas, kamus bahasa Indonesia tidak mengakomodasi konsep "spiritualitas", namun mencantumkan "spiritual", yang didefinisikan sebagai berhubungan dengan kejiwaan, rohani, batin, sesuatu yang tidak berhubungan dengan materi (Departemen Pendidikan Nasional, 2011). Maka spiritualitas dalam beragama dapat dipahami sebagai aspek kejiwaan, batin, atau rohani dari kepercayaan kepada Tuhan. 
Selanjutnya, spiritualitas kebertuhanan tersebut selain diwarnai oleh adanya keyakinan akan adanya Tuhan, juga diwarnai oleh pengakuan akan keistimewaan manusia di antara mahluk-mahluk Tuhan lainnya yang membuat manusia mengemban tugas untuk menjadi wakil atau khalifah Allah (Frager, 2012), mewakili-Nya dalam menebar rahmat dan kasih sayang di dunia, dan mengatur alam semesta sesuai dengan kehendak Tuhan. Menjadi wakil artinya bahwa dalam posisi tersebut, semua perilaku yang dilakukan terkait posisinya idealnya dilakukan dengan "atas nama yang diwakilinya". Hal itu tercermin dalam pernyataan yang lazim dinyatakan mendahului setiap perilaku individu Islam yaitu "atas nama Allah Yang Maha Pengasih dan Maha Penyayang". Keyakinan bahwa Tuhan adalah realitas yang "ada", dengan segala atribut yang terkait, adalah elemen pertama dari diri yang religius.

Konsep self berikutnya yang menginspirasi konstruksi konsep diri religius adalah relational self (Andersen \& Chen, 2002), yang mengasumsikan bahwa setiap individu memiliki sejumlah penghayatan self yang masing-masing tumbuh dan berkembang melalui relasinya dengan orang lain sepanjang kehidupannya. Argumentasi sentral relational self adalah bahwa self pada dasarnya relasional, berhubungan dengan pihak signifikan, dan relasi tersebut berdampak pada personality functioning. Dalam relational self, pengetahuan seseorang tentang dirinya berhubungan dengan pengetahuannya tentang orang lain yang signifikan baginya, serta pengetahuannya akan setiap hubungan yang membangun relasi diri-orang lain (selfother).

Syarat pengetahuan mempersyaratkan kapasitas individu untuk mengaktivasi representasi mental mengenai mitra relasi yang signifikan baginya, baik dalam kehadiran fisik maupun kehadiran simbolik dari orang tersebut. Konstruk relational self tersebut menginspirasi penulis dalam hal konstruksi self yang melibatkan keterhubungan individu secara konsisten dengan faktor eksternal di luar dirinya. Untuk relational self, faktor tersebut adalah significant others, sedangkan untuk religious self, mitra relasinya adalah Tuhan, atau representasi simbolik yang dikonstruksinya tentang Tuhan. Proses psikologis yang terjadi dalam diri religius relatif sama dengan proses psikologis dalam relational self, yaitu adanya pemikiran (thought), perasaan (feeling), motif (motives), dan strategi pengelolaan diri (self regulatory) yang mempertimbangkan keterhubungan dengan mitra relasinya. Kesadaran diri akan keterhubungan dengan Tuhan ini adalah salah satu elemen dari diri religius (elemen ke-2).

Oleh karena kehadiran Tuhan bagi individu bersifat simbolis, maka konteks ketika seorang individu terhubung dengan Tuhan sangat individual dan sangat spiritual. Disebut bersifat individual karena situasinya seperti ketika seseorang memegang telepon genggam setiap saat dan ia memiliki kendali untuk menghubungi seseorang. Ada individu yang merasa selalu terkoneksi dengan Tuhan (bisa dianalogikan dengan fasilitas whatsapp yang statusnya "ada", siap dihubungi setiap saat). Sedangkan pada individu lain ia hanya menghayati terhubung dengan Tuhan dalam situasi-situasi yang ia telah tetapkan sendiri waktu dan konteksnya, misalnya ketika berdoa dan ketika berada di dalam tempat ibadah. Disebut bersifat spiritual karena Tuhan tidak hadir dalam suatu wujud, melainkan dalam bentuk simbolis atau citra, yang bisa dirasakan secara sangat yakin dan mantap, namun bisa pula samar-samar, tidak jelas, atau bahkan tidak terasa sama sekali. Kualitas kehadiran Tuhan bagi individu sangat dipengaruhi oleh kesadaran yang dibentuk oleh internalisasi individu terhadap pengaruh agama melalui budaya, lingkungan eksternal, dan faktor sosialnya. 
Telaah teori self pada sekitar dua dekade terakhir memang menunjukkan kecenderungan peningkatan pesat di dunia Timur, dengan pendekatan yang melibatkan budaya secara lebih komprehensif. Kecenderungan tersebut muncul sebagai respon atas sejumlah hasil penelitian bahwa individu pengguna bahasa yang berbeda, memiliki cara pandang yang berbeda dalam menerima dunia, termasuk penghayatan atas diri dan orang lain (Yang \& Bond, 1990).

Perkembangan teori self oleh ahli dari belahan dunia Timur didasari oleh perhatian Markus dan Kitayama (2003) pada perbedaan budaya Barat dan Timur dalam memandang individu. Budaya Barat memandang individu sebagai bersifat independen, terikat hanya pada dirinya sendiri (self-contained), suatu kesatuan otonom yang tersusun dari sejumlah atribut internal yang membentuk konfigurasi unik, dan bertingkah laku atas dasar atributatribut internal tersebut. Para ahli psikologi yang berasal dari dunia Timur memandang bahwa tidak tepat untuk menggambarkan selfhood individu di dunia Timur dengan melepaskan individu tersebut dari konteksnya (Markus \& Kitayama, 2003). Setidaktidaknya begitulah yang mereka rasakan sebagai orang Jepang dengan shintoisme-nya.

Masyarakat di Timur akan selalu menghayati dirinya sebagai bagian dari konteks budayanya, dan secara tidak langsung berarti menghayati dirinya sebagai bagian dari masyarakatnya, bahkan bagian dari alam semesta. Penghayatan atau paradigma itu adalah predisposisi yang membuat individu di belahan dunia Timur memiliki self yang terhubung (relational self), termasuk terhubung dengan yang dianggap sebagai pencipta alam semesta, apapun konseptualisasinya (Tuhan, Master of The Universe, Allah, Brahman, Thian). Penulis memiliki pandangan yang sama, yaitu bahwa orang lain dan dunia eksternal di luar diri individu, sangat penting dalam pengalaman individual seseorang dari budaya Timur, sedemikian rupa sehingga dalam menghayati dirinya, individu tersebut selalu menempatkan dirinya dalam posisi relasional. Self yang menghayati keterhubungan dengankonteks sosial dibahas oleh Markus dan Kitayama yang mendefinisikannya sebagai self-inrelation-to-other.

Karakteristik self individu dapat mempengaruhi secara sistematis aspek kognisi, emosi, dan motivasi (Markus \& Kitayama, 2003), misalnya bahwa pada aspek motivasi, individu dengan self construal independen akan cenderung mengembangkan self-serving motives, sedangkan mereka yang interdependent self construal cenderung mengembangkan other-serving motives. Religious self, sebagai self dengan construal yang terhubung secara dependen kepada Tuhan, akan mengikuti kecenderungan serupa, dalam hal ini adalah God-serving motives, yaitu suatu situasi ketika seseorang memiliki motif untuk menampilkan perilaku yang berorientasi pada "menyenangkan Tuhan" (dalam bahasa Islamnya: berorientasi pada "mendapatkan ridlo Allah"). Ketika motif tersebut konsisten atau keberadaannya relatif stabil pada konstruksi self seseorang, maka dapat dikatakan bahwa self-nya religius, atau kualitas religious self-nya "tinggi" berdasarkan elemen tersebut. Elemen tersebut akan menjadi elemen ke-3 dari diri religius.

Individu yang selalu merasa dalam keadaan terhubung dengan orang lain akan berusaha menjaga keterhubungannya dengan mengendalikan diri untuk menyelaraskan dirinya dengan orang-orang yang signifikan baginya. Maka dalam diri yang religius mekanisme psikisnya akan sama, yaitu penghayatan keterhubungan dengan Tuhan akan membuat seseorang berusaha menjaga hubungannya dengan Tuhan melalui pengendalian diri agar perilakunya selaras dengan kehendak Tuhan (akan menjadi elemen ke-4 dari diri religius). Morry dan 
Kito menyebut self yang karakteristiknya seperti itu sebagai self yang konstruksinya bersifat relasional-interdependent (Morry \& Kito, 2009).

\section{Relational-interdependent self-} construal (RISC) is the tendency to think of oneself in terms of relationships with close others, and it influences relationship cognitions (e.g., closeness, commitment, perceived similarity) (Morry \& Kito, 2009).

Penulis merujuk konsep relationalinterdependent self-construal karena struktur self-nya serupa dengan pemikiran penulis mengenai religious self, yaitu bahwa seorang muslim lazimnya adalah selalu berada dalam kesadaran akan suatu hubungan yang tidak terpisahkan dengan Tuhan. Namun, dalam religious self, sifat hubungannya bukan saling tergantung (interdependence) sebagaimana yang terjadi dalam relational-interdependence self, melainkan sifat hubungannya ketergantungan sepihak, yaitu dependensi individu pada Tuhan, atau relasionaldependen.

Diri religius adalah sistem self yang strukturnya dibangun oleh kesadaran keterhubungan individu dengan Tuhan secara relasional-dependen. Kalaupun ada kesaling tergantungan, pengertiannya menurut pendapat penulis adalah bahwa citra atau sifat Tuhan bagi individu ditentukan oleh masingmasing individu, bukan citra obyektif Tuhan. Maka, tergantung pada citra yang dibangun oleh individu itulah karakteristik keterhubungan diri-Tuhan ditentukan. Dalam Islam, Allah memperkenalkan dirinya memiliki 99 sifat, namun sifat mana yang dihayati oleh seorang muslim dalam penghayatan keterhubungannya dengan Tuhan, adalah pilihan bebas pada individu, sedangkan pada pihak Tuhan, Ia Menyatakan bahwa "Aku seperti persangkaan hamba-Ku kepada-Ku". Berdasarkan hal tersebut, maka dapat dikatakan bahwa karakteristik self-nya adalah relational-(meta)interdependent self, yaitu suatu keterhubungan dimana sikap pihak mitra relasi (Allah) kepada individu akan tergantung pada sikap individu terhadap-Nya.

\section{Akhlaqul Karimah dan Diri Religius}

Konsep akhlak sudah dikenal dalam bahasa Indonesia dengan pengertian yaitu budi pekerti atau kelakuan, sedangkan karimah diterjemahkan sebagai baik dan terpuji (Departemen Pendidikan Nasional, 2011). Dengan demikian, akhlaqul karimah dapat dipahami sebagai suatu budi pekerti yang baik dan terpuji. Konsep budi pekerti atau kepribadian yang baik tersebut dalam terminologi Islam muncul dalam pernyataan Nabi Muhammad S.A.W yang maknanya adalah "Sesungguhnya aku diutus untuk menyempurnakan akhlak yang mulia" (Ghazali, 1988).Interpretasi psikologis atas pernyataan itu adalah bahwa tujuan dari beragama Islam adalah untuk mengembangkan kepribadian agar mencapai kepribadian dengan kualitas yang baik. Dalam bahasa self, agar individu muslim mencapai kualitas diri atau jiwa yang religius, atau yang religious self-nya tinggi. Tesis yang diajukan penulis tentang diri religius adalah semakin tinggi atau semakin kuat diri religius, semakin positif pikiran, perasaan, motif, dan perilakunya, untuk diri sendiri maupun orang lain. Diri religius yang tinggi akan memiliki daya untuk memfungsikan mekanisme kontrol dan regulasi atas pikiran, perasaan, motif, dan perilaku.

Berdasarkan kajian konseptual tentang diri religius, penulis mengajukan empat elemen yang terdapat dalam strukturnya, yaitu 1) spirit atau keyakinan kebertuhanan (Godness belief), 2) kesadaran akan keterhubungan dengan Tuhan (God-self relationship awareness), 3) penerimaan akan adanya kehendak Tuhan pada diri (perceived God's intention), dan 4) motif berperilaku yang diorientasikan pada penjagaan hubungan diri-Tuhan (God-serving motives). 


\section{Iman dan Keyakinan Kebertuhanan}

Bahasa Indonesia memiliki tiga makna yang terkait dengan iman, yaitu 1) kepercayaan (yang berkenaan dengan agama), 2) keyakinan dan kepercayaan kepada Allah, nabi, kitab, dan sebagainya, serta 3) ketetapan hati, keteguhan batin, dan keseimbangan batin (Departemen Pendidikan Nasional, 2011). Berdasarkan ketiga makna tersebut, maka penulis melihat iman sebagai suatu agregat psikis berupa keyakinan yang disertai dengan ketetapan dan keteguhan. Terminologi psikologi tradisional yang analog dengan konsep iman adalah belief. Lebih spesifik dari itu yaitu iman kepada Allah dengan demikian analog dengan Godness belief, keyakinan yang kuat akan keberadaan Allah dan sifatsifat ketuhanannya.

Perspektif diri religius menempatkan keyakinan kebertuhanan sebagai elemen pertama yang membangun strukturnya.Posisi keyakinan sebagai elemen pertama tersebut sejalan dengan posisi iman menurut $\mathrm{Al}$ Qur'an, yaitu di dalam hati, sebagaimana dalam QS. 8/2 "Sesungguhnya orang-orang yang beriman itu adalah mereka yang apabila disebut Allah gemetarlah hatimereka, dan apabila dibacakan kepada mereka ayat-ayatNya, bertambahlah iman mereka (karenanya) dan kepada Tuhanlah mereka bertawakal". Ayat tersebut menggambarkan diaktivasinya elemen-elemen psikis tertentu oleh stimulus yang bersifat kebertuhanan, pada diri orang yang memiliki iman kepada Allah, keyakinan kebertuhanan, atau Godness belief. Negasinya, aktivasi tersebut tidak akan terjadi pada individu yang tidak memiliki pondasi tersebut, yaitu keyakinan kebertuhanan atau iman.

Al-Qur'an menyebutkan elemenelemen psikis yang diaktivasi oleh memori atau stimulus tentang kebertuhanan, antara lain amal shalih (QS. 29/9 yaitu "Dan orangorang yang beriman dan mengerjakan amalamal shalih...", dan takwa (QS. 33/70-71)
"Wahai orang-orang yang beriman, bertakwalah kalian kepada Allah dan katakanlah perkataan yang benar, niscaya Allah memperbaiki bagi kalian amalanamalan kalian.".

Amal shalih didefinisikan dalam bahasa Indonesia sebagai perbuatan yang sungguh-sumgguh dalam menjalankan ibadah atau menunaikan kewajiban agama (Departemen Pendidikan Nasional, 2011), sedangkan takwa memiliki makna terpeliharanya diri untuk tetap taat melaksanakan perintah Allah dan menjauhi segala larangan-Nya. Pengertian etimologis mengenai amal shalih dan takwa sebagai aspek psikis yang diaktivasi oleh iman menunjukkan bahwa kualitas elemen iman atau keyakinan dalam diri religius seseorang akan memungkinkan self memiliki fungsisebagai pengontrol (self control) dan meregulasi (self regulatory) perilaku, dalam hal ini adalah perilaku penjagaan diri untuk melakukan yang sejalan dengan keyakinan kebertuhanannya dan mengarahkan diri untuk menjauhi yang sebaliknya. Pembahasan ini, sebagaimana secara eksplisit tertera pula dalam QS. 33/70-71, akan terkait dengan pembahasan tentang takwa, yang analog dengan elemen keempat dari diri religius, yaitu motif berperilaku yang diorientasikan pada penjagaan hubungan diri-Tuhan.

\section{Ihsan}

Secara bahasa Indonesia, penulis mengalami bahwa ihsan tidak lazim digunakan dalam percakapan sehari-hari, namun ternyata dalam kamus bahasa Indonesia konsep tersebut ada dan diartikan sebagai "baik" (Departemen Pendidikan Nasional, 2011). Pengertian tersebut sejalan dengan terjemahan al-Qur'an tentang muhsinin, yaitu QS. 29/69, yang menerjemahkannya sebagai "orang yang berbuat kebaikan", demikian pula seperti tertera dalam QS. 16/128, 
yaitu“...sesungguhnya Allah beserta orangorang yang bertakwa dan berbuat kebaikan”.

Penulis mendapatkan pengertian lain tentang ihsan yang kurang lebih bermakna bahwa ihsan adalah suatu kesadaran diri yang konsisten untuk meyakini bahwa ia selalu melihat Allah, dan ketika ia tidak mampu menyadari penglihatan tersebut, maka ia perlu menyadari bahwa Allah melihatnya. Pada dasarnya, tidak mungkin seseorang tidak melihat Allah, jika ia menyadari bahwa semua materi yang bisa dilihat adalah ciptaan (creature), yang pasti ada yang menciptakannya (creator), semua yang ada dalam dirinya maupun di luar dirinya, adalah ciptaan dari Allah. Allah pasti mudah dilihat dalam pengertian melihat Allah melalui ciptaan-Nya.

Pengertian tersebut mengandung kesadaran akan keterhubungan seorang individu muslim dengan Allah. Teori diri religius mengkonseptualisasinya dengan Godself relation awareness, atau kesadaran akan adanya keterhubungan antara diri seseorang dengan Tuhan. Kesadaran keterhubungan, sebagaimana yang terjadi pada konstruk self yang interdependen dan relasional (Markus \& Kitayama, 2003), akan membuat pemilik selfnya berupaya menjaga keterhubungan tersebut melalui pengendalian perilaku dalam situasi interaksi. Morry dan Kito berargumen bahwa kesadaran keterhubungan tersebut akan mempengaruhi pemikiran keterhubungan (relationship cognition), antara lain perasaan dekat dan komitmen (Morry \& Kito, 2009).

\section{Tawakal}

Konsep tawakal juga sudah diserap ke dalam bahasa Indonesia, dengan pengertian yaitu pasrah diri kepada kehendak Allah; percaya dengan sepenuh hati kepada Allah; berserah diri kepada kehendak Allah (Departemen Pendidikan Nasional, 2011). Penulis memiliki ketertarikan pada terminologi "kehendak Allah" dalam konsep tawakal tersebut, dengan memperluas pengertiannya meliputi "perintah, himbauan untuk melakukan, himbauan untuk tidak melakukan, dan larangan". Berserah diri pada kehendak Allah, berdasarkan pandangan penulis, mengandung pengertian keberserahan diri untuk menerima perintah, himbauan, dan larangan Allah. Dalam konsepsi diri religius, ini adalah elemen ketiga, yaitu penerimaan akan kehendak Tuhan pada diri (perceived God's intention).

Keberserahan diri untuk mengikuti perintah, mematuhi himbauan, dan menghindari larangan, logikanya akan memunculkan efek linier berupa motif untuk mengekspresikannya dalam bentuk perilaku. Maka konsep ini akan terkait dengan elemen berikutnya, yaitu takwa. Besarnya efek perilaku yang bisa termanifestasikan ketika tawakal ini dimiliki oleh seorang individu, ditunjukkan oleh besarnya reward yang dikaitkan dengan tawakal tersebut (QS. 65/3 “...barangsiapa yang bertawakal kepada Allah niscaya Allah akan mencukupkan (keperluan)nya.").

Al-Qur'an juga memberikan petunjuk tentang "kepada siapa" ketawakalan atau keberserahan diri atau self pada pihak eksternal tersebut harus ditujukan, yaitu kepada Allah (QS. 3/122) “...Karena itu hendaklah kepada Allah saja orang-orang mukmin bertawakal'). Kenyataan bahwa sistem self yang bekerja pada individu bisa terdiri hanya satu sistem, misalnya sistem self yang religius, namun bisa pula pada diri seorang individu bekerja lebih dari satu sistem self, yang disebut sebagai multiple self, composite self (Yang, 2006)atau segregated self (Glock \& Stark, 1969). Dalam konteks bahwa keluhuran akhlak adalah sesuatu yang perlu diperjuangkan untuk dicapai agar menjadi semakin mendekati sempurna, maka pernyataan (QS. 3/122) tersebut menandakan bahwa Allah Mengetahui kemungkinan 
adanya competing self yang bekerja pada diri seseorang, dan ketika itu terjadi, maka keberserahan diri kepada Tuhan-dalam bahasa self berarti mengaktivasi sistem religious self dan bukan yang lain- adalah pilihan yang harus diambil. Perintah Allah, “...hendaklah kepada Allah saja orang mukmin bertawakal". Kualitas diri religius akan ditentukan ketika elemen perilaku terpenuhi, yaitu takwa.

\section{Takwa}

Takwa memiliki dua arti, yaitu sebagai terpeliharanya diri untuk tetap taat melaksanakan perintah Allah SWT dan menjauhi segala larangan-Nya; dan kesalehan hidup (Departemen Pendidikan Nasional, 2011). Sedangkan berdasarkan perspektif Islam, konsep takwa berasal dari bahasa Arab at taqwa dengan asal katanya adalah al wiqayah yang berarti melindungi atau menjagadiri dari kemaksiatan atau perbuatan dosa(al-Ghazali, 2008).

Sejumlah ayat al-Qur'an yang dirujuk dalam pembahasannya tentang taqwa antara lain: (QS. 4/131) yaitu “...bertakwalah kepada Allah...”, (QS. 9/36) “...Bahwasannya Allah beserta orang-orang yang bertakwa.", (QS. 9/4) "Sesungguhnya Allah menyukai orang-orang yang bertakwa.”, (QS. 5/27) "...Sesungguhnya Allah hanya menerima (amalan) dari orang-orang yang bertakwa”, (QS. 16/128) "Sesungguhnya Allah beserta orang-orang yang bertakwa dan orang-orang yang berbuat ikhsan (kebaikan)”, (QS. 65/23) “...Barangsiapa yang bertakwa kepada Allah, niscaya Dia akan mengadakan baginya jalan keluar dan Memberinya rizki dari arah yang tidak disangka-sangka”, (QS. 64/16) "Maka bertakwalah kamu kepada Allah menurut kesanggupanmu...”, (QS. 3/123) “...bertakwalah kepada Allah, supaya kamu mensyukuri-Nya”. Referensi takwa dalam bahasa kamus dan analisis Al-Ghazali, melalui frasa "melaksanakan perintah Allah", "amalan orang yang bertakwa", dan "bertakwa menurut kesanggupan", mengedepankan istilah yang mengandung pengertian "pelaksanaan perilaku" atau tindakan, dalam hal ini adalah tindakan yang terkait dengan iman (QS. 33/70-71) dan ihsan (QS. 16/128). Interpretasi psikologinya adalah, takwa merupakan faset dari diri religius yang mengaktivasi perilaku, dikonseptualisasi secara perspektif psikologi dengan konsep "motif berperilaku". Karakteristik perilaku yang dimaksud dalam elemen ini adalah perilaku yang mencerminkan keterkaitan dengan elemen lain dari diri religius, yaitu elemen keyakinan kebertuhanan dan elemen penerimaan akan keberkehendakan Tuhan.

Bagan 1. di bawah ini memvisualisasikan keterkaitan konstruksi diri religius dengan akhlaqul karimah

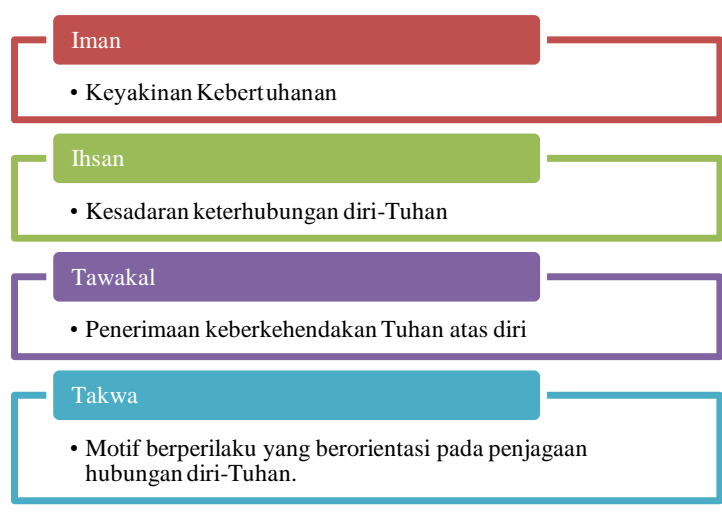

Bagan 1. Konstruksi Diri Religius Dengan Akhlaqul Karimah

Bagan di atas menggambarkan bahwa struktur diri religius dapat dijelaskan dengan fitur-fitur akhlaqul karimah. Oleh karenanya, maka kualitas karakteristik pada diri religius pada kontinum antara diri religius "rendah" dengan diri religius "tinggi" juga dapat diprediksikan analog dengan kualitas akhlaq pada kontinum akhlaqul karimah yaitu antara akhlaqul mazmumah (tercela) dengan akhlaqul mahmudah (terpuji). Deskripsinya adalah, bahwa semakin tinggi diri religius 
seorang muslim, semakin sikap dan perilakunya didasari oleh kesadaran akan posisinya sebagai hamba Tuhan, meliputi kesediaan untuk menerima secara positif peristiwa yang dialaminya dan kesediaan untuk patuh pada aturan Tuhan yang diyakininya.

Sebaliknya, semakin rendah religiusitas diri seorang muslim, semakin sikap dan perilakunya tidak dipengaruhi oleh kesadaran bahwa ia adalah seorang hamba Tuhan, melainkan ia menjadi penentu atas hidupnya dan pengalamannya sendiri, tidak merasa bahwa ada aturan Tuhan yang harus ia patuhi.

\section{SIMPULAN}

Melalui interpretasi psikologis atas iman, ihsan, tawakal, dan takwa, maka dapat dikatakan bahwa dalam perspektif konsep diri religius, akhlaqul karimah atau budi pekerti luhur, adalah kualitas ideal dari diri religius. Ia merupakan konstruksi psikis yang memiliki struktur keyakinan kebertuhanan (iman) sebagai pondasinya, kesadaran keterhubungan diri-Tuhan (ihsan), dan penerimaan keberkehendakan Tuhan atas diri (tawakal).Elemen struktur yang terakhir adalah motif berperilaku yang berorientasi pada penjagaan hubungan diri-Tuhan (takwa), yang juga merupakan dimensi perilaku atau amal. Keempat elemen struktur tersebut berinteraksi secara dinamis membentuk kualitas dari strukturnya, dengan dinamika yang bisa saling memperkuat atau saling memperlemah. Semakin kuat interaksi antar elemen, semakin besar daya self-nya untuk mencapai kualitas akhlaqul karimah.

Deklarasi Nabi Muhammad SAW dalam salah satu hadits bahwa beliau diutus oleh Allah untuk menjadi perantara penyempurnaan akhlak manusia, mengandung makna bahwa akhlak adalah agregat dinamis dalam diri manusia yang bisa bergerak, menuju ke arah yang semakin sempurna yang diidentifikasi sebagai kualitas akhlaqul karimah, dan tentu logikanya bisa juga menuju ke arah sebaliknya. Pernyataan tentang dinamisasi akhlak tersebut sejalan dengan perspektif psikologi tentang sistem self, dimana diri religius adalah salah satu sub sistem self dalam diri individu yang bisa bersifat dominan terhadap sub sistem self yang lain sehingga kendali dan pengarahself diwarnai secara masif oleh diri religiusnya. Namun bisa jadi bahwa diri religius bukan satu-satunya karakteristik self yang ada dalam diri seseorang.

Seseorang bisa memiliki sub sistem self lain yang bekerja sebagai competing selfterhadap diri religius, misalnya social self, atau cultural self. Oleh karena itu,untuk menjadikan diri religius menjadi sub sistem self yang dominan, maka sub sistem tersebut harus diperkuat melalui penguatan keempat elemen diri religius secara konsisten. Dalam terminologi Islamnya berarti melakukan penguatan iman, ihsan, tawakal, dan takwa, sedangkan dalam terminologi psikologinya berarti memperkuat elemen keyakinan, kesadaran keterhubungan, penerimaan kehambaan, dan motif penjagaan kualitas relasi diri-Tuhan, atau yang dikonseptualisasi sebagai religious belief, God-self relationship awareness, acceptance of God's intention to self, dan motives of obedience to God's order.

\section{DAFTAR PUSTAKA}

Abdul Rauf, I. F. (2004). What's Right with Islam: A New Vision for Muslims and the West. (D. Mardina, \& M. R. Atmoko, Trans.) New York: HarperCollins.

Al-Ghazali, I. (2008). Minhajul Abidin: Jalan para ahli ibadah. (I. Ba'adillah, M. Alkatiri, Eds., \& A. H. as-Sasaky, Trans.) Jakarta: Khatulistiwa Press.

Andersen, S. M., \& Chen, S. (2002). The Relational Self: An Interpersonal Social-Cognitive Theory. 
Psychological Review, 109(4), 619645.

Bennett, M. (2011, July/August). Children's social identities. Infant and Child Development, 20(4), 353-363.

Boucher, H. C. (2010). Understanding Western-East Asian Differences and Similarities in Self-Enhancement. Social and Personality Psychology Compass, 4(5), 304-317.

Calhoun, J. F., \& Acocella, J. R. (1990). Psychology of Adjustment and Human Relationships (3rd ed.). New York, USA: McGraw Hill Publishig Company.

DeMarree, K. G., Petty, R. E., \& Brinol, P. (2007, 1 1). Self and Attitude Strength Parallels: Focus on Accessibility. Social and Personality Psychology Compass, 441-468.

Depag. (1984). Al Qur'an dan Terjemahnya. Jakarta: Departemen Agama Republik Indonesia.

Departemen Pendidikan Nasional, P. B. (2011). Kamus Besar Bahasa Indonesia (4th ed.). Jakarta: Departemen Pendidikan Nasional.

Frager, R. (2012). Sufi Talks: Teachings of an American Sufi Sheikh (Terjemahan ed.). (H. Akmal, Trans.) Weathon: Quest Books.

Ghazali, I. (1988). Ihya Ulumiddin (Vol. 4). (I. Yakub, Trans.) Kuala Lumpur: Victory Ajensi.

Glock, C. Y., \& Stark, R. (1969). Religion and Society in Tension. Rand McNally \& Company.

Markus, H., \& Kitayama, S. (2003). Culture and the Self. Implication for Cognition, Emotion, and Motivation. In M. A. Hogg, Social Psychology (Vol. IV). London: SAGE Publications.

Morry, M. M., \& Kito, M. (2009, June). Relational-Interdependent

Self-
Costrual as a Predictor of Relationship Quality: The Mediating Roles of One's Own Behaiors and Perceptions of the Fulfillment of Friendship Functions. The Journal of Social Psychology, 149(3), 205-222.

Ng, H, S., Ha, S. M., \& Lai, J. C. (2010). Dynamic bicultural brains: fMRI study of their flexible neural representation of self and significant others in response to culture primes. Asian Journal of Social Psychology, 13, 8391.

Nola, R., \& Sankey, H. (2007). Theories of Scientific Method: An Introduction. Stocksfield: Acumen Publishing Limited.

Quinn, N. (2006). The Self: Anthropological Theory. Journal of Historical Sociology, 6(3), 362-384.

Reber, A. (1985). Dictionary of Psychology. USA: The Penguin Books.

Schlegel, R., \& Hicks, J. (2011, 12 5). The True Self and Psychological Health: Emerging Evidence and Future Directions. Social and Personality Psychology Compass, 5(12), 9891003.

Schmeichel, B. J., Vohs, K. D., \& Baumeister, R. F. (2003). Intellectual Performance and Ego Depletion: Role of the Self in Logical Reasoning and Other Information Processing. Journal of Personality and Social Psychology, 85(1), 33-46.

Smither, R., \& Khorsandi, A. (2009). The Implicit Personality Theori of Islam. Psychology of Religion and Personality, I(2), 81-96.

Yang, K., \& Bond, M. (1990). Exploring Implicit Personality Theories With Indigenous or Imported Constructs: The Chinese Case. Journal of Personality and Social Psychology, 58(6), 1087-1095. 
12| Psikis : Jurnal Psikologi Islami Vol. 5 No. 1 Juni 2019

Yang, L. \&. (2006). the chinese high school student's stress in the school and academic achievement. educational psychology. International Journal of Experimental Educational Psychology, 31(1). 